\title{
Constructing Stereotypes in Media: A Critical Analysis on the Representation of Women in Tanzanian Newspapers
}

\author{
Stanley Elias \\ Faculty of Humanities \\ Airlangga University \\ Surabaya, Indonesia \\ stanleyelias86@yahoo.com
}

\begin{abstract}
Over centuries the history of women representation in media is a plethora of stereotypes and stigmatisation. Findings from studies confirm that media do produce and reproduce ways of seeing our culture. In this light, this study sets out to critically analyse the representation of women in selected Tanzanian newspapers. The study particularly interrogates ways in which media discourse serves as avenue to construct women gendered stereotypes and stigmatisation to the community. Two selected newspapers namely, Ijumaa and HabariLeo were analysed through Critical Discourse Analysis and Semiotics Frameworks. Through analysis and interpretations of the selected newspapers it can be argued women representation is ideologically representative of the existing power relations that affects the women subgroup in the Tanzanian society. Thus, women representation in the selected newspaper is ascribed with gendered stereotyped and appendage roles compared to their counterparts to appeal men consumers and those with male-defined interest. However, with increasing efforts to impart awareness on equality and women rights today significant progress in ascribing women with positive roles is underway in the same way to appeal taste of the consumers of the service and products.
\end{abstract}

Keywords-media; newspaper; stereotyped gender roles; women and power relations

\section{INTRODUCTION}

Since the $19^{\text {th }}$ century the history of women representation in media is a plethora of stereotypes and stigmatisation. According to[1] before the $19^{\text {th }}$ century there was no such a noticeable disparity between men and women representation in media. Traces of women stereotyping in media go back in 1890s when a section special for "women issues" was developed to appeal women readers of the newspapers[2]-[4]. [5]points that the section for women's issues covered engagements and weddings, food recipes, beauty sections and tips for being a good homemaker. According to [6]these "women issues" were considered appropriate for women and those with female defined interest as opposed to "hard news" which were appropriated for men. Consequently, the labelling of the media content influenced the understanding, attitudes and beliefs towards women identities in media across time and space. In fact, besides the basic roles of informing, educating and entertaining, media also were found to produce and reproduce beliefs towards our society and others and more importantly beliefs towards women subgroups in our societies [2], [7]-[9]. Of a particular note, what is often seen or read in media is a selection reflecting particular priorities, views and ideological constructs that underlie a worldview of the society ([10], [11] Thus, its selection and presentation in specific media output, produce and reproduce certain assumptions, status and roles about women in their cultural settings[10]. In the light of this paper, I set out to interrogate the ways in which Tanzanian newspapers discourse influence(s) construction of women gendered stereotypes and stigmatisation to the community.

According to [12] though there is a fluid nature of socially constructed gender traits about women and men, some societies have a fairly stable general idea about what women and women should be like, what is most appropriate for them to do, say, feel or like. In fact, societies construct and sustain frameworks within which the majority of men and women fit regardless of their specific personal traits[12]-[14]. "Or else, society creates and sustains certain gender stereotypes, which differ across cultures considerably, but are more or less common for the majority of people in a particular part of the world[12]". Thus, gender is conceived to be socially constructed behaviors of how men and women should do in the society and gender stereotype is beliefs about the psychological traits and characteristics of, as well as the activities appropriate to, men or women[1], [8], [15]. More importantly, gender stereotypes are framed within the beliefs and attitudes about masculinity and femininity ideologies[1]. On the other hand, media is argued to be one of the pillars that mirror, influence and create or recreate gender roles and gender stereotypes of the society in place. The influence of media in producing and reproducing ways of seeing our culture and of course in producing and reproducing stereotypes of cultural groups in the society should not be underestimated[16], [11], [17], [18]. Thus, the media form under study is expected provide an avenue to understand culture as well as stereotypes of men and women in the Tanzanian community. 


\section{PRINT MEDIA IN TANZANIA}

Historically print media in Tanzania started as far as back in 1888 when the first newspaper Masimulizi(The Storyteller) was published by Anglican Universities' Mission to Central Africa (UMCA) in Zanzibar[19]. Since the inception of Masimulizi, print media industry in Tanzania went through four major phases namely the German colonial phase, the British colonial phase, the independence struggle phase and the post-colonial phase. Each media phase had media outlets mainly print media that served to agitate interests of the respective governments and institutions in the named phases[19]. After the independence of Tanganyika (currently Tanzania) efforts to establish printing and publishing houses for media outlets were initiated by the independent government. Again, in the phase of independent Tanzania print media went through other sub-phases to the now modern print media. Today, print media is ranked second after radio in terms of accessibility to majority Tanzanians[16]. Of course it has been of appealing magnitudes to literate people of different ages in different parts of the country.

In terms of the print media concerns[19] explains that before trade liberalization (before 1990) most newspapers concentrated on "important matters" of the nation like agriculture, education, politics, health and other of the same weight. In similar view [10] argues that in the late 1980s and early 1990s print media, broadsheets in particular, had "concentrated on "serious issues" like politics, economics and social issues like health services, education and the like and with only a few pages dedicated to sports and entertainment”. [10] notes that today's newspapers are dealing with "soft news”, entertainment and sports. According to [20], [10]today's newspapers deal with matters that were previously considered taboos such as sex and related scandals in such a way it has proliferated out to a serious separate publishing business. This has been the case of most tabloids. Of all the "taboos" in the newspapers, women have have been the most victims due to social set ups of many Tanzanian societies. According to[21] the cultural myth subjects women into social structure and power relation trap and so their representation in newspapers is a reflection of what the society believes and behaves towards women. [22] puts that it is ideology that justifies power over women and so replicating what [23]argued earlier. Reiterating [22] it is argued that there are cultural assumptions that women are not naturally protagonists of stories or history and humanity's story is essentially of men and this has influence on perceptions and coverage of women in print media[21]. Corroboratively,[24]argues that images or representations in media pervades and supports the patriarchal ideologies by portraying women in kinder nature. This study particularly interrogates ways in which media discourse serves as avenue to construct women gendered stereotypes and stigmatisation to the community. The study selects two newspapers namely, Ijumaa and HabariLeo ${ }^{1}$ which will be

1 The choice of the two newspapers is based on the fact their concerns, mode and style of presentation differ from each other. Ijumaa newspaper is privately owned that is released on weekly basis. It is one the popular and favorites analysed through Critical Discourse Analysis and Semiotics Theoretical Frameworks

\section{CONSTRUCTING GENDER STEREOTYPES IN THE NEWSPAPERS}

As pointed earlier, the power of media in producing and reproducing certain patterns of our lives is vivid across cultures in space and time. Indeed, media, newspapers in particular act as agents of socialization of certain behaviour and beliefs from one generation to another. [16] points that media have now been performing roles of socialization that it was traditionally done mainly through social institutions like family, schools, political and economic institutions. Reiterating the power of media in reference to newspaper, [20] argues that media can constructively or destructively exert its influence in the way we understand ourselves and others in the society. [10] argues that media remains and are increasingly one of the forces for influencing societal attitudes and stereotypes. Thus, this section of the paper devotes to critically analyse the construction of gender stereotypes with assumptions that media permeates behaviour, attitudes and beliefs towards understanding of women roles in the society.

\section{A. Women are as sexual objects in the society}

[25]points out that media mirrors and influences beliefs and attitudes towards understanding of women. In Ijumaa newspaper women are depicted as sexual objects. In most cases, their costumes, postures of their images and their general portrayal in the tabloid is ascribed to sexual related interest. Fig. 1 shows images of beautiful women on front page of the newspaper. Most often images of most attractive women would appear on front pages of the newspaper and thus the newspaper has formed identity among others in representing women in similar trend. Also the accompanying texts to pictures like "MBUNGE: WEMA KAUMBIKA JAMANI!" (Member of the Parliament (male) praises that Wema is very sexy for sure)is fronted on the newspaper to praise how beautiful the woman is. This findings echoes to what [10] found that read newspapers in Tanzania have been in most cases represented as sexual objects. Sometimes the newspaper has been accused by women rights activists for putting nude pictures (picha za nusu uchi) of women on its front page and elsewhere as they stigmatise women in the society unlike men. Of a particular note, [20] argue that the dominant male ideologies in media have been affecting women representation in media and so it is the case of Ijumaa newspaper. newspaper (tabloids). HabariLeo on the other hand is government owned which is released on daily basis. 


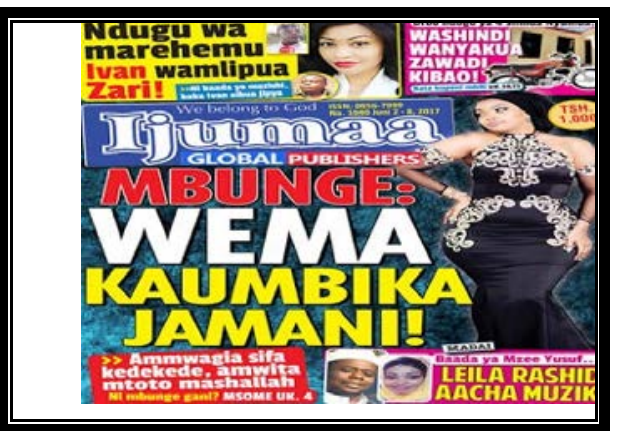

Fig. 1. Women on front page of Ijumaa newspaper of June 2017

\section{B. Only beautiful and young girls matter in the society}

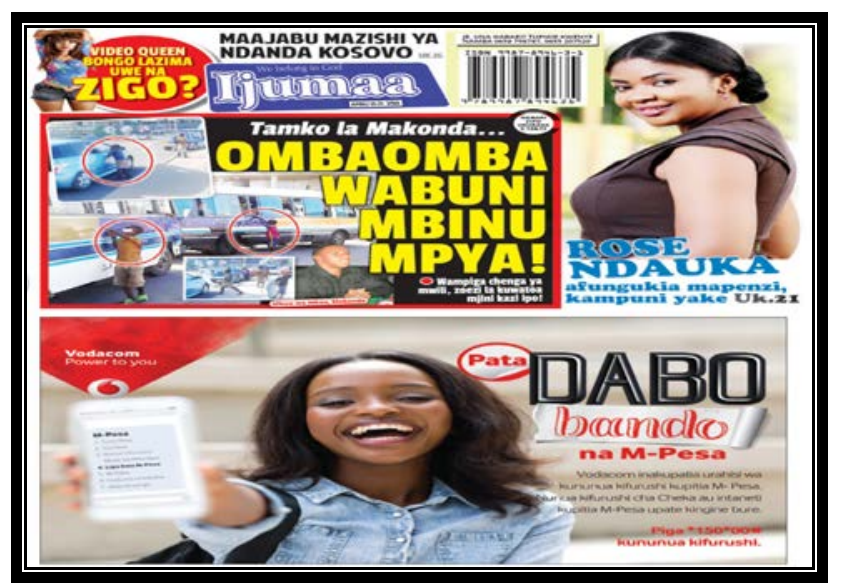

Fig. 2. Young and beautiful girls Ijumaa newspaper

As in the foregoing discussion, it is now becoming accustomed that media is for young and beautiful girls. In Tanzanian settings young, beautiful and attractive women are used to colour front pages of the newspaper and in commercials or promotions or public appearances to attract readers and consumers of the service in commercials. [26] corroborates on the observation and he provocatively argues that the use of beautiful a young girls in media is to reward male consumers and which is already constituted in the social structure. Fig.2 echoes such a belief as women are ascribed with beauty and sex related contents. This can be a special way of marketing the newspaper and other services the advertised in the newspaper. [19][10]point that this patterned representations of young and beautiful girls is ideological representative of the hegemonic relationships between men and women in most societies in Tanzania as they define and places women in pleasure of men.

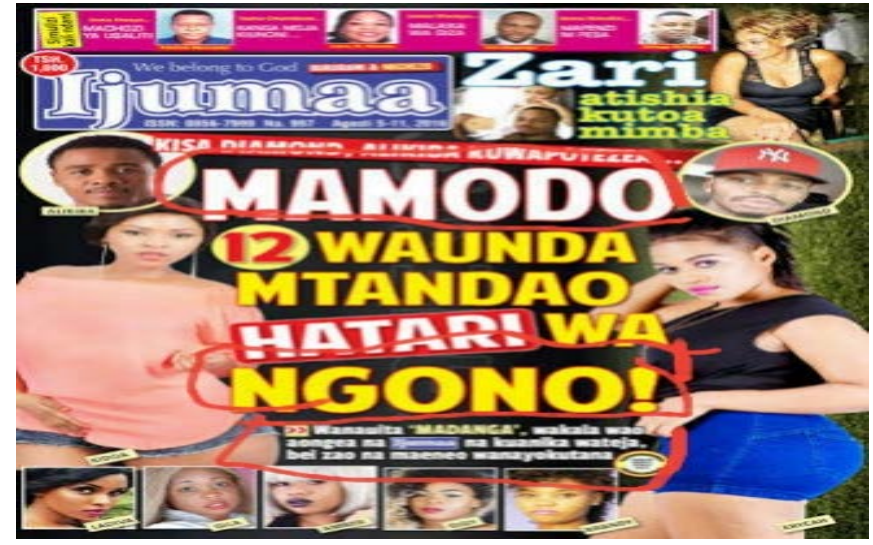

Fig. 3. Portrayal of women financial dependence over men

\section{Financial dependence over men}

While the traditional view of gender roles prescribe women to nurture and being bound to household's tasks, men are ascribed with economic power to supply basic needs and any other financial support to women. However, in the modern Tanzanian societies women have sorted to look for any economic opportunities that would make them financial stable. On the contrary of their efforts, the society's view is ascribing their efforts to promiscuity(Madanga) as in the fig. 3. Any financial success for a woman is related to "Udangaji" (promiscuity) ${ }^{2}$.Of course, [27] states that;

\section{"men are presumed by traditional view of masculinity gender roles to be heads of their households by providing financially for the family and making important decisions".}

This traditional view on gender roles subject women in financial dependence point of view even when they manage to stand in their own. As in fig. 3 video vixen and fashion designers (MAMODO) are linked to promiscuity as source of income they only manage to have.

\section{Assessing Changes of Women Portrayal In Print MEDIA}

With increasing efforts to bring equality in the societies from the government, human rights activists, religious institutions and other non-government organizations, the current trend on women stereotypes in newspapers is promising. However, this has been evident mainly those newspapers that are owned by the government and other broadsheets that deal with "hard news". As noted earlier, the establishment of tabloid's industry provided newspapers with identities in terms of which content they do deal with. In the contrary of Ijumaa newspaper, HabariLeo is in some ways deconstructing the traditional views and stereotypes of women in the society. For instance in the fig 4 . while in most families

\footnotetext{
${ }^{2}$ Udangaji is a tendency whereby women engage in sexual relationships with different men (popularly these men are referred to 'sponsors') for financial gains.
} 
women bear all blames when a husband and wife fail to get children, it is men who are found to be the source of the problem. "Ugumba watesa zaidi wanaume" (Infertility affects men more than): 'Daktari bingwa ashangaa wanawake kuandamwa" (A specialist is surprised to see women being accused). The newspaper deconstructs the social traditional view where women are victimized of childless (infertility) even when the source of the problem is not from their side (women).

Also as pointed out earlier that this newspaper is owned by the government, it acts as an agent to transform policies into practices especially policies that perpetuate equality and not stereotypes and stigmatisation of women in the society. As of this reason, often the representation of women in HabariLeo is somehow free from gendered stereotypes and stigmatisation.

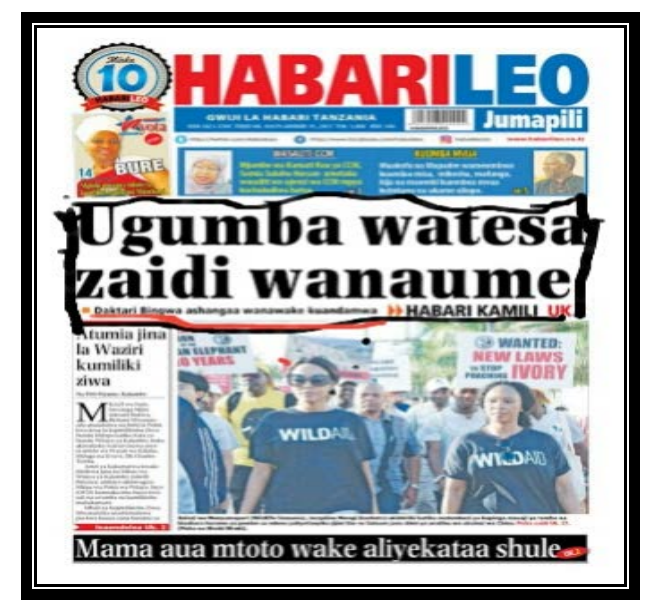

Fig. 4. Deconstruction of traditional view on infertility over women.

\section{CONCLUSION}

As per discussion, it can be argued that the power of newspaper in constructing gendered stereotypes and stigmatisation in the society should not be underrated. Central to the analysis newspaper have influenced and produced certain meanings towards women. These meanings are representative of the ideological constructs and hegemonic relationships as women and men associate in the society.

\section{REFERENCES}

[1] R. Brannon, “Gender Stereotypes: Masculinity and femininity,” pp. 159-185, 1976.

[2] R. A. Kerin et al., "Women in advertisements : Retrospect and Prospect,” J. Advert., vol. 8, no. 3, pp. 37-42, 1979.

[3] N. M. B. T. J. A. Isanovic, Stereotyping: representation of women in print media in south east europe. 2006.

[4] J. E. Owens and T. P. Hawes, "Language choice and the representation of women and men in two British newspapers," Journal. Discourse Stud., vol. 1, no. 1, pp. 1-22, 1995.

[5] C. L. Armstrong, "Writing about women: An examination of how content for women is in newspapers.," Mass Commun. Soc., vol. 9, no. 4, pp. 447-460, 2006.

[6] A. Fahs, "Newspaper women and the making of the modern, 18851910," 2005.

[7] A. C. Chi and C. Baldwin, "Gender and Class Stereotypes; A Comparison of U . S . and Taiwanese Magazine Advertisements," Race, Gend. Class, vol. 11, no. 2, 2004.

[8] N. Ellemers, "Gender Stereotypes," 2017.

[9] D. Espinosa, "Running head: gender roles in the media i gender roles in the media and debunking society's stereotypes:," 2010.

[10] E. Solomon, "Women' s roles in the media: attitudes towards gender issues in six Tanzanian newspapers," no. september, 2006.

[11] A. Hajimohammadi, "Critical analysis of women 's representation in tv advertisements from a cultural studies perspective," int. $\mathrm{j}$. women"s res., vol. 1, pp. 107-122, January 2011.

[12] D. Popova, "Gender stereotypes in advertising," p. 5, 2010.

[13] B. D. Kivel, "To address ideology, hegemony and the power of representation in leisure studies research, we offer memory-work," no. 1997, 1998.

[14] D. Kellner, "Reading images critically," in gender, race and class in media. a text reader, J. M. G. Dines, G. \& Humez, Ed. 1995.

[15] H. J. M. Dines, G., "A cultural studies approach to gender, race, and class in media," Cult. Stud., pp. 1-7, 1995.

[16] E. N. Shartiely, "The portrayal of the Tanzanian woman in television commercials : is she a piece of soap , a house , or gold ?," Africa Asia, vol. 5, no. 5, pp. 108-141, 2005.

[17] A. Kumari and H. Joshi, "Gender stereotyped portrayal of women in the media: perception and impact on adolescent," IOSR J. Humanit. Soc. Sci. Ver. II, vol. 20, no. 4, pp. 44-52, 2015.

[18] A. Furnham and S. Paltzer, "The portrayal of men and women in television advertisements: An updated review of 30 studies published since 2000,” Scand. J. Psychol., vol. 51, no. 3, pp. 216236, 2010.

[19] M. Sturmer, The Media history of Tanzania. Mtwara: Ndanda Mission Press, 2008.

[20] J. Morna, C. and Mufune, "Media on the a gender. audit of the southern Africa: Declaration on gender and development," in DS Media., 2002.

[21] C. Rivers, "Bandwagons, women and cultural mythology," Media Stud., vol. 7, no. 1-2, pp. 1-17, 1993.

[22] C. Barker, “An Introduction to cultural Studies,” Cult. Stud. Theory Pract., vol. 01, no. 1, pp. 1-38, 2012.

[23] A. Gramsci, History, philosophy and culture in the young Gramsci. Telos Press, 1975

[24] L. Paulson, "Mama bears, bitches and monsters: Motherhood and violence in popular film," in Featuring females: Feminist analyses of media, \& J. D. E. Cole, Ed. Washington DC: American Psychological Association., 2005.

[25] A. Sharda, "Media and Gender Stereotyping: The need for Media Literacy,” Int. Res. J. Soc. Sci. ISSN Int. Res. J. Soc. Sci, vol. 3, no. 8, pp. 2319-3565, 2014.

[26] D. Warren, “Commercial liberation,” J. Commun., vol. 28, no. 1, pp. $169-173,1978$.

[27] A. M. Blackstone, "Gender roles and society,” Hum. Ecol. An Encycl. Child. Fam. Communities, Environ., pp. 335-338, 2003. 